\title{
DETECTION OF CYANIDES IN THE PRESENCE OF FERRO- AND FERRICYANIDES AND THIOCYANATES.
}

\author{
BY O. L. BARNEBEY. \\ Received March 25, 1914.
}

The reaction upon which this detection is based is the solubility of copper sulfide in solutions of alkali cyanides. When hydrogen sulfide is passed into a dilute ammoniacal cupric solution a precipitate of cupric sulfide is formed, or a deep blue to brownish black coloration is imparted to the solution, depending upon the amount of hydrogen sulfide dissolved, the temperature, and the dilution of the solution. The addition of an alkaline cyanide clears this suspension or colored solution. The copper solution can be made so dilute that the test becomes quite delicate, much more delicate than the bleaching of the blue solution of copper ammonia compounds, and has the additional merit of not being interfered with seriously by ferro- or ferricyanides, or thiocyanates.

An ammoniacal copper solution was prepared by dissolving I.25 g. $\mathrm{CuSO}_{4.5} \mathrm{H}_{2} \mathrm{O}$ in water, making ammoniacal and diluting to a liter. Each cubic centimeter of this solution is equivalent to about $0.000473 \mathrm{~g}$. of hydrocyanic acid on the basis of the following reaction, which, however, is empirical:

$$
\begin{aligned}
& 2\left[\mathrm{CuSO}_{4} \cdot 4 \mathrm{NH}_{3}\right]+7 \mathrm{KCN}+{ }_{7} \mathrm{H}_{2} \mathrm{O}= \\
& 2 \mathrm{~K}_{2} \mathrm{Cu}(\mathrm{CN})_{3}+\mathrm{KCNO}+\mathrm{K}_{2} \mathrm{SO}_{4}+\left(\mathrm{NH}_{4}\right)_{2} \mathrm{SO}_{4}+6 \mathrm{NH}_{4} \mathrm{OH}
\end{aligned}
$$

The test is performed as follows: A bubble or two of hydrogen sulfide gas is passed into, or a few drops of hydrogen sulfide water are added to a small quantity of the standard copper solution, the amount of this depending upon the delicacy desired. This suspension is then added to the unknown ammoniacal solution (or vice versa) with constant shaking. If the color is bleached, the presence of a cyanide is indicated. The addition of the ammoniacal copper solution is continued until no further bleaching is noticed. From the volume of copper solution used an approximate quantitative estimation can be made. With care, one can add a few cubic centimeters of dilute hydrogen sulfide water in the cyanide titration of copper at the instant of bleaching and obtain a coloration which is then bleached with more cyanide, making a moderately accurate end point. In the presence of ferrocyanides, however, the reaction is not quantitative, inasmuch as the ferrocyanide is oxidized to ferricyanide more or less completely during titration.

The color caused by $\mathrm{O}$. I cc. of the copper solution in a volume of $5 \mathrm{cc}$. is bleached by $0.2 \mathrm{cc}$. of a 0.0 I $N$ solution of $\mathrm{KCN}$ when the test is made as above indicated, which means a delicacy of about r.o parts HCN per hundred thousand.

In the presence of $50 \mathrm{cc}$. of a solution of $\mathrm{KCNS}$ (equivalent to $2 \mathrm{~g}$.) $0.5 \mathrm{mg}$. of $\mathrm{HCN}$ can be detected; 50 cc. of a $4 \%$ solution of $\mathrm{K}_{\mathrm{s}} \mathrm{Fe}(\mathrm{CN})_{6}$ 
(2 g.) allows a detection of I mg. of $\mathrm{HCN}$; while $50 \mathrm{cc}$. of a $4 \%$ solution of $\mathrm{K}_{4} \mathrm{Fe}(\mathrm{CN})_{6},(i . e ., 2 \mathrm{~g}$.) will likewise permit a detection of $0.5 \mathrm{mg}$. of $\mathrm{HCN}$. In the presence of small quantities of the above cyanogen compounds the test is reliable to $0.1 \mathrm{mg}$. of $\mathrm{HCN}$.

In the presence of smaller amounts of ferro- or ferricyanides the test becomes correspondingly more delicate. When the test is applied to solutions containing much ferricyanide, one should add as much copper solution to a blank, containing approximately the same amount of ferricyanide, as to the solution being tested for cyanide and the difference in shade should be noted, or the quantities of copper solution necessary to give a certain depth of color should be compared.

For the average requirements of qualitative analysis, tenth-normal copper sulfate solution will suffice.

Inasmuch as the test gives a decided reaction for relatively small amounts of cyanides, and also furnishes an indication of the relative amount present in the solution examined, as well as being applicable in presence of other cyanides, this test is proposed for general qualitative purposes.

Department of ANalytical, Chemistry,

UnIVERSity of Wisconsin, Madison.

[Contribution from the Analytical, Laboratory, Coliege of the City of New YORK.]

A NEW PROCEDURE FOR THE SEPARATION OF THE COPPER AND TIN GROUPS.

By Louis J. CURTMan aNd Joseph K. Marcus. Received February 20, 1914.

Despite the many shortcomings of the ammonium polysulfide method for the separation of the copper and tin groups, no procedure has ever been devised whereby a sharp separation of these groups from each other might be obtained. The objections to the ammonium polysulfide method, as shown by the work of A. A. Noyes, ${ }^{1}$ are as follows:

I. Ammonium polysulfide dissolves some copper sulfide ${ }^{2}$ and mercuric sulfide, ${ }^{3}$ thus making the separation of these metals incomplete, and at the same time causing confusion by their precipitating with the metals of the tin group.

2. Under certain conditions a large quantity of $\operatorname{tin}^{4}$ remains undissolved by the ammonium polysulfide.

1 This Journal, 29, I70.

${ }^{2} 5$ to ro mg. of copper may dissolve in the ammonium polysulfide when a large amount of copper is present.

${ }^{3} 0.5$ to $\mathrm{I} \mathrm{mg}$. of mercury may dissolve in ammonium polysulfide when a large amount of mercury is present.

4When large quantities of elements of the copper group and only 3 to $5 \mathrm{mg}$. of tin are present, the whole of the tin may remain undissolved and when much cadmium is present, together with tin in the stannous state, as much as $15 \mathrm{mg}$. of the latter may be left in the residue. 